\title{
Welcome to Biomedicine Hub
}

'If a new result is to have any value, it must unite elements long since known, but till then scattered and seemingly foreign to each other, and suddenly introduce order where the appearance of disorder reigned.' Wilfred Bion

We are extremely excited and passionate about our new journal Biomedicine Hub. Why? Simply consider how many times you have seen the phrase interdisciplinary cooperation is required'. This phrase is often used as an almost cliché sign-off at the end of a biomedical paper that provides no clear definition of 'interdisciplinary cooperation', much less effective strategies that can be used to measure or achieve it.

This is why we need 'an interdisciplinary "global hub" for researchers, clinicians, and public health professionals'. Not wanting to simply publish articles in isolation, Biomedicine $H u b$ strives to tease out the wider implications of each finding or idea we publish, and thus help clinicians and researchers find inspiration and ideas from outside their own fields of expertise. Ultimately, this innovative interdisciplinary approach should improve the health and well-being of patients.

Our vision is not restricted to the lateral connections seen through interdisciplinary communication, but also examines the vertical path from 'bench to bedside to the population'. This is crucial: we want to draw on expertise from all the necessary stakeholders to approach biomedical problems - from basic researchers through to the clinician and the public health professional.

As a Karger journal, we have over 125 years of experience in publishing cutting-edge science. However, as just stated, knowledge is not enough - connection is crucial. So, what else do we need to achieve our vision? In the spirit of looking to other fields (and practicing what we preach), let us draw upon a model from the business world. For Biomedicine Hub to achieve our vision, we need three things: the right people, the right processes, and the right technology.

Our international Editorial Board of highly regarded researchers and clinicians across a vast range of disciplines (http://www.karger.com/Journal/EditorialBoard/261421) clearly demonstrates that we have the right people. We are experimenting with new processes to 
help draw out the full implications of each finding, insight, and opinion that we publish. Through this, we can help share best practices between clinicians and provide researchers with examples and analogies from other fields. Finally, we are constantly examining new advances in publishing technology. In particular, we are seeking ways to assist you condense the 2.5 million articles that get published per year down to the most valuable 300 that you are likely to read and benefit from. A mammoth challenge, but an important one we are sure you will agree!

Biomedicine Hub has laid the foundation for a new interdisciplinary, global, scientific and medical community. Come and be a part of it. Please submit articles, ideas for articles, highlight new developments, and visit us on social media and leave comments. Biomedicine Hub is a service for you - we invite you to help us shape it.

Julie Y.H. Chan, Kaohsiung Samuel H.H. Chan, Taipei

Fiammetta Cosci, Florence David M. Gardiner, Irvine, Calif.

Maik Gollasch, Berlin

Marta Gwinn, Atlanta, Ga.

Jörgen Isgaard, Göteborg Kam Kalantar-Zadeh, Irvine, Calif. George P. Patrinos, Patras Israel Rubinstein, Chicago, Ill. Michael Schmid, Würzburg Michael P. Sherman, Columbia, Mo. Hans-Uwe Simon, Bern Constantine A. Stratakis, Bethesda, Md. Marcel Tanner, Basel Kurt S. Zaenker, Witten 